\title{
NAO signal recorded in the stable isotopes of Greenland ice cores
}

\author{
B. M. Vinther, S. J. Johnsen, K. K. Andersen, H. B. Clausen, and A. W. Hansen \\ Niels Bohr Institute of Astronomy, Physics and Geophysics, University of Copenhagen, Copenhagen, Denmark \\ Received 29 August 2002; revised 8 November 2002; accepted 3 January 2003; published 8 April 2003.
}

[1] The winter $\delta^{18} O$ signal is extracted from 7 Greenland ice cores covering the past $\sim 700$ years. To filter out noise and local variations in the 7 isotope records a principal component analysis is carried out on the ice core data. A comparison between the time series of the first principal component (PC1) with 67 years of winter (December to March) temperature measurements from 3 southern Greenland synoptic stations shows highly significant correlations. Southern Greenland winter temperatures are known to be greatly influenced by the North Atlantic Oscillation (NAO). A good proxy for southern Greenland temperatures is therefore expected to reveal at least parts of the NAO signal. It is shown that the PC1 time series indeed is significantly correlated to the NAO during the winter months. The inclusion of ice core winter season $\delta^{18} O$ time series in future multiproxy NAO reconstructions is therefore recommended. INDEX TERMS: 3309 Meteorology and Atmospheric Dynamics: Climatology (1620); 1620 Global Change: Climate dynamics (3309); 3344 Paleoclimatology; 9315 Information Related to Geographic Region: Arctic region; 9325 Atlantic Ocean. Citation: Vinther, B. M., S. J. Johnsen, K. K. Andersen, H. B. Clausen, and A. W. Hansen, NAO signal recorded in the stable isotopes of Greenland ice cores, Geophys. Res. Lett., 30(7), 1387, doi:10.1029/2002GL016193, 2003.

\section{Introduction}

[2] The North Atlantic Oscillation (NAO) is known to have a large influence on climate in the North Atlantic region It is therefore desirable to extend our knowledge of past variability of the NAO far back in time. However pressure measurements at the NAO's two centers of action (Iceland and the Azores/Iberia) are available for the last $\sim 180$ years only. Reconstructions of the NAO based on early European instrumental and documentary data reaches back to 1500 A.D. [Luterbacher et al., 1999; 2002] leaving documentary and natural proxies for meteorological data as the only means of reconstructing the NAO prior to around 1670 [Luterbacher et al., 2002].

[3] In recent years a variety of annually resolved proxy based NAO indices has been presented, but only in a few cases [Glueck and Stockton, 2001; Cook et al., 2002] they reached back beyond 1500 A.D.

[4] Greenland winter climate is known to be heavily influenced by the NAO and studies over the last 10 years show a connection between the NAO and climate records from Greenland ice cores [e.g., Barlow et al., 1993; White et al., 1997; Appenzeller et al., 1998a, 1998b and Rogers et al., 1998]. Rogers et al. [1998] showed that winter stable isotope data from central Greenland firn cores relates very

Copyright 2003 by the American Geophysical Union. 0094-8276/03/2002GL016193\$05.00 well to the NAO during 29 winters (1959-1987). Appenzeller et al. [1998a, 1998b] found significant correlations between NAO indices and annual accumulation data from Greenland ice cores.

[5] This paper presents a time series for mid to southern Greenland temperature spanning the winters from 1245 to 1970 A.D. The time series is so far the only available annually resolved proxy for the NAO reaching to the early 13th century. Principal component analysis and stacking are applied to winter season $\delta^{18} \mathrm{O}$ data from 7 ice cores drilled in southern, western, eastern and central Greenland in order to obtain the time series. Methods that have already proven useful in isolating temperature related signals from multiple $\delta^{18} O$ ice core records [Fisher et al., 1996].

[6] An investigation of how the derived proxy temperature time series compares with the North Atlantic region circulation and temperature patterns is also presented.

[7] Finally relations between the derived proxy temperature time series and two NAO indices will be examined. The two NAO indices are based on instrumental pressure data [Jones et al., 1997] (NAO-J) and a variety of early instrumental and documentary data [Luterbacher et al., 1999, 2002] (NAO-L) respectively.

\section{Ice Core Isotope Data and Temperature}

[8] The isotopic ratio $\delta^{18} O$ measured in ice cores can be used as a temperature proxy because of the temperature dependent fractionation of oxygen isotopes, that takes place while moisture travels from its evaporation area to the Greenland ice sheet [Dansgaard, 1964; Johnsen et al., 1989]. Hence climate oscillations on long time scales such as glacial and interglacial periods as well as DansgaardOeschger events are clearly identified from ice core $\delta^{18} \mathrm{O}$ records. Determining temperature variations on annual and seasonal time scales is however complicated by the fact that $\delta^{18} \mathrm{O}$ data are biased by accumulation, i.e. the temperature proxy is only recorded during precipitation events. Nevertheless Steffensen [1985] showed that when omitting temperature data from periods without precipitation, the $\delta^{18} O$ record from the Dye 3 ice core compares very well to Greenland coastal temperatures during the period 19801983 even on monthly time scales.

[9] Using ice core $\delta^{18} O$ records dating back hundreds of years it is however not possible to make corrections for accumulation inhomogeneities. Although disregarding the effects of variations in accumulation obviously leads to noise in $\delta^{18} \mathrm{O}$ based proxy temperature records, White et al. [1997] found a highly significant correlation coefficient of $\mathrm{r}=0.471$ between a stacked central Greenland isotope record and $\sim 100$ years of coastal Greenland annually averaged temperatures. Even on seasonal time scales Barlow et al. [1997] and Rogers et al. [1998] found significant 


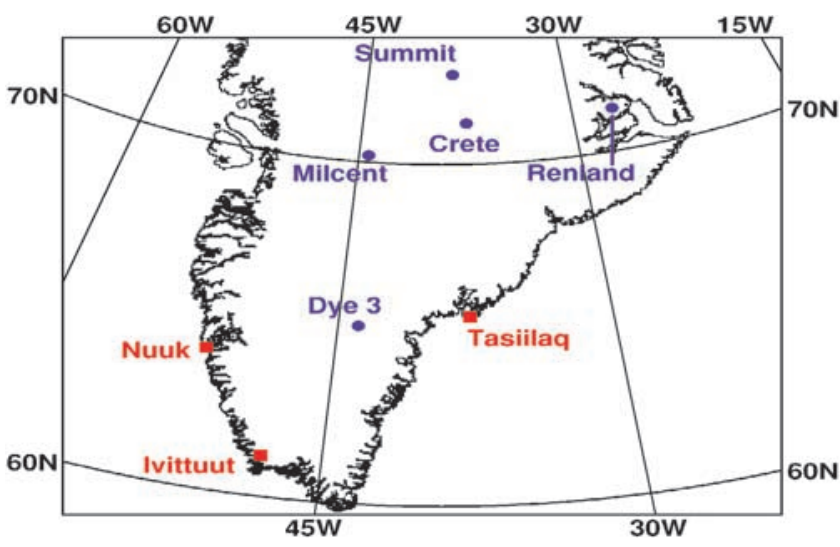

Figure 1. Location of the Greenland ice core drill sites (blue) and temperature stations (red) used for this survey.

correlations between central Greenland isotope ice core records and temperature measured at Greenland coastal synoptic stations.

\section{The Greenland Ice Core Data}

[10] Ice core data from 5 different drill sites in the southern half of Greenland have been analyzed: Crete, Dye 3, Milcent, Renland and Summit (2 cores from the Dye 3 area: Dye 379 and Dye 371 and 2 cores from the Summit area: GRIP 89-1 and GRIP 93) [Hammer et al., 1978; Johnsen et al., 1992; White et al., 1997]. Figure 1 shows the location of the drill sites while Table 1 provides details concerning the ice cores. All cores reach at least 800 years back; except for the Dye 371 ice core where the oldest layer is from 1244 . The youngest discernible winter in the Milcent core dates back to 1970 .

\subsection{The Role of Diffusion}

[11] Firn diffusion in the top $\sim 55$ meters of the ice cores tends to smooth out $\delta^{18} O$ seasonal variations [Johnsen et al., 1999]. Hence back-diffused $\delta^{18} O$ data is preferable in comparison with raw data when examining seasonal signals in the $\delta^{18} O$ records. We will therefore use back-diffused data whenever possible. The method of back-diffusion is however vulnerable to melt layers in the ice cores, forcing one to use raw $\delta^{18} O$ data for three ice cores (the two Dye 3 cores and the Renland core) containing several melt layers. Due to high accumulation at the Dye 3 and Renland drill sites (see Table 1) the annual cycle at these sites is less damped and back-diffusion thus not essential.

\subsection{Extraction of the Winter Isotope Signal}

[12] The isotopic year is defined between two adjacent minima of the (back-diffused) isotope profile. We here chose to base winter $\delta^{18} O$ data on the first sixth of the $\delta^{18} \mathrm{O}$ data from a given isotopic year and the last eighth of the year before. The mean of the winter $\delta^{18} O$ values is calculated for each year. Hence $\sim 29 \%$ of the annual accumulation is used to define winter values.

[13] Having extracted winter $\delta^{18} O$ means for each winter in each ice core for the period 1245-1970 (the time period covered by all the ice cores) we turn to principal component analysis (PCA) to isolate a common regional signal. To avoid biasing the PCA by the three cores from the central Greenland ice divide (Crete, GRIP 89-1 and GRIP 93) or the two Dye 3 cores, we chose to stack these into a "central" and a "southern" core respectively. Furthermore the linear trends (caused mostly by diffusive damping of the annual $\delta^{18} O$ cycle) are removed from all cores to avoid biasing.

[14] The PCA is then carried out for the total time period covered by all four cores (the southern, western (Milcent), eastern (Renland) and central core) i.e. 726 years. The weights on the four cores when forming the principal components are given in Table 2. The table also shows the variance explained by each component. From Table 2 it can be seen that all four ice cores contribute to the first principal component (PC1) with the same sign. Hence the time series of the $\mathrm{PC} 1$ represents a truly regional signal explaining $36 \%$ of the total variance in the four cores. Because the ice core $\delta^{18} O$ records have a red spectrum it is important to note that PCA applied to four noise series with approximately the same red spectrum as the ice cores would give a PC1 explained variance of only $32 \%$ [Fisher, 2002; pers. comm.]. The ice core PC1 is therefore not simply produced by noise.

\section{Winter Isotope Data Compared to Northern Hemisphere Climate}

\subsection{Comparison of the PC1 Time Series With Greenland Temperature Data}

[15] To evaluate how well the time series of the PC1 captures southern Greenland winter (Dec-Mar; year of Jan) temperatures, three synoptic stations with records extending back to the late 19th century were selected for comparison: Tasiilaq, Ivittuut and Nuuk (station locations are shown in Figure 1) [Frich et al., 1996; Peterson and Vose, 1997].
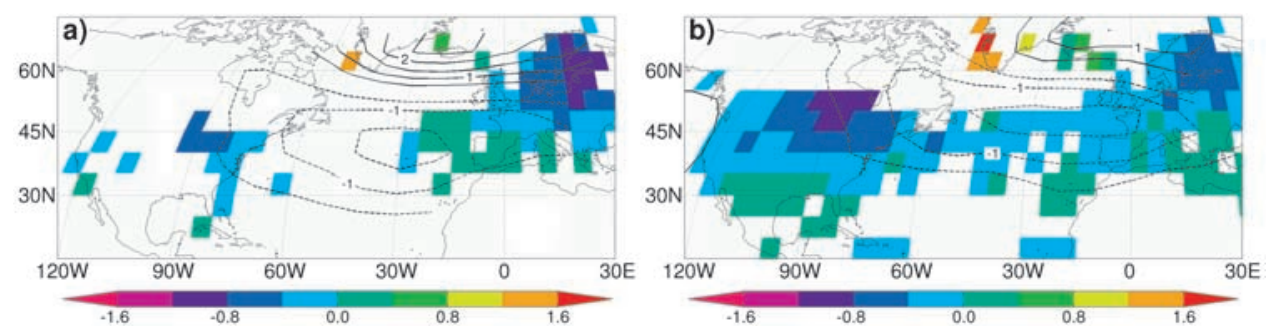

Figure 2. The spatial response of surface pressure (contours in $\mathrm{hPa}$ ) and temperature (scale in ${ }^{\circ} \mathrm{C}$ ) corresponding to a $1 \sigma$ increase in the ice core PC1 time series. (a) is based on a linear regression of the PC1 time series versus CRU Dec-Mar surface pressure and temperature data for 1874-1970 and 1857-1970 (year of Jan) respectively. (b) as for (a) but only for Dec-Mar 1897-1926 (see text for details). Grid points with more than 10\% missing temperature data are left blank. 
Table 1. Ice Core Characteristics

\begin{tabular}{|c|c|c|c|c|c|c|c|c|}
\hline Ice Core & $\begin{array}{c}\text { Elevation } \\
\text { m a.s.1. }\end{array}$ & $\begin{array}{c}\text { Latitude } \\
{ }^{\circ} \mathrm{N}\end{array}$ & $\begin{array}{c}\text { Longitude } \\
{ }^{\circ} \mathrm{W}\end{array}$ & $\begin{array}{c}\text { Mean air } \\
\text { temp. in }{ }^{\circ} \mathrm{C}\end{array}$ & $\begin{array}{l}\text { Accumulation } \\
\text { m ice per year }\end{array}$ & $\begin{array}{c}\text { Ice Core } \\
\text { length in } \mathrm{m}\end{array}$ & $\begin{array}{l}\text { Oldest } \\
\text { layer }\end{array}$ & $\begin{array}{c}\text { Year core } \\
\text { drilled }\end{array}$ \\
\hline Crete & 3172 & 71.12 & 37.32 & -30 & 0.30 & 404 & 554 A.D. & 1974 \\
\hline Dye $371^{\mathrm{a}}$ & 2480 & 65.18 & 43.83 & -20 & 0.56 & 372 & 1244 A.D. & 1971 \\
\hline Dye 379 & 2480 & 65.18 & 43.83 & -20 & 0.56 & 2037 & B.C. ${ }^{\text {b }}$ & 1979 \\
\hline GRIP 89-1 & 3230 & 72.58 & 37.64 & -32 & 0.23 & 260 & 920 A.D. & 1989 \\
\hline GRIP 93 & 3230 & 72.58 & 37.64 & -32 & 0.23 & 230 & 1063 A.D. & 1993 \\
\hline Milcent & 2450 & 70.30 & 44.55 & -22 & 0.53 & 398 & 1177 A.D. & 1973 \\
\hline Renland & 2350 & 71.57 & 26.73 & -18 & 0.50 & 325 & B.C. ${ }^{b}$ & 1988 \\
\hline
\end{tabular}

a Youngest layer in Dye 371 main core is 1951. The nearby Dye $34 \mathrm{~B}$ core is used for the years from 1951 to 1970.

${ }^{\mathrm{b}}$ The core was drilled to bedrock. Oldest layers $\sim 100,000$ years old.

Pearson correlations between station temperatures and the PC1 time series can be seen in Table 3 (To make intercomparison possible correlations were calculated only for 67 winters were measurements from all three stations were available; namely 1895-1966 except 1901, 1911, 1919, 1927 and 1928).

[16] As a measure of the southern Greenland temperature a simple mean was calculated for the three synoptic stations. The correlation between the PC1 time series and this southern Greenland temperature (Table 3) is $r=0.75$. This suggests that the PC1 time series captures $56 \%$ of southern Greenland winter temperature variance.

\subsection{Comparison With North Atlantic Region Winter Circulation}

[17] To investigate how changes in North Atlantic region surface circulation and temperature patterns relate to the PC1 time series, two gridded data sets from the Climatic Research Unit (CRU), Norwich, UK are used: The CRU $5^{\circ}$ latitude by $10^{\circ}$ longitude monthly mean sea level pressure data set [Jones, 1987] (start January 1873) and the $5^{\circ}$ by $5^{\circ}$ "HADCRUT" temperature data set (start January 1856), that combines land and sea surface temperatures [Jones et al., 1997]. For each year Dec-Mar means are derived from the two CRU data sets and subsequently used to obtain spatial responses of surface pressure/temperature (Figure 2a) to a $1 \sigma$ increase in the PC1 time series. The responses were calculated by means of linearly regressing grid point surface pressure/temperature against the PC1 time series.

[18] It is clear that the North Atlantic region surface pressure response shown in Figure 2a compares very well to the NAO pressure structure (centers of action over Iceland and the Azores/Iberia). The surface temperature patterns found from the regression does also resemble NAO teleconnection patterns containing excursions of opposite sign in southern Greenland versus Europe and the eastern U.S.

\subsection{Comparison With NAO Indices}

[19] For long term analysis of the connection between northern hemisphere winter circulation and the ice core PC1 time series a comparison with NAO indices is performed.

Table 2. Ice Core Weights on Principal Components

\begin{tabular}{lcccc}
\hline & PC1 & PC2 & PC3 & PC4 \\
\hline East & 0.10 & 0.98 & 0.07 & 0.17 \\
West & 0.60 & -0.20 & 0.44 & 0.64 \\
Central & 0.65 & 0.05 & 0.21 & -0.73 \\
South & 0.46 & -0.01 & -0.87 & 0.16 \\
Var. exp. & $36 \%$ & $25 \%$ & $22 \%$ & $16 \%$ \\
\hline
\end{tabular}

[20] Pearson correlations between the PC1 time series and the NAO-J index as well as the NAO-L index are shown in Table 3. The PC1 time series is correlated at the 99.99\% significance level (all significance levels are based on a standard t-table) to both NAO indices (Dec-Mar means) in the periods $1824-1970$ for the NAO-J index and 1659-1970 for the NAO-L index.

[21] As shown by Schmutz et al. [2000] correlations between NAO indices and proxy data such as the ice core based PC1 time series should be calculated not only for the maximum time period possible but also in smaller subperiods. This is to investigate the stability of the relation between a given proxy and the NAO. Hence 30 year running Pearson correlations between the PC1 time series and the two NAO indices are presented in Figure 3.

[22] The PC1 time series is significantly correlated at the 95\% level to the Dec-Mar mean NAO-J index for 116 out of a total of 120 30-year subsets. With regard to the DecMar mean NAO-L index correlations are significant at the $95 \%$ level for 203 out of 28530 -year subsets. The nonsignificant correlations between the PC1 and the NAO-J for the 1896-1928 sub-periods could be a consequence of a weakened relation between the NAO and northern hemisphere surface temperatures during that period [Osborn et al., 1999]. It should however be noted that even in the subperiod 1897-1926 where the least significant correlation $(\mathrm{r}=-0.30)$ between the PC1 and the NAO-J is observed, surface pressure/temperature response patterns to changes in the PC1 time series still contain many NAO characteristics (see Figure 2b).

\section{Conclusions}

[23] From Greenland ice core winter season $\delta^{18} O$ data it is possible to reconstruct more than half of the variance found in southern Greenland Dec-Mar mean temperatures during the period 1895-1966 using PCA techniques.

Table 3. Pearson Correlations Between Climate Variables and the PC1 Time Series

\begin{tabular}{lcc}
\hline \multicolumn{1}{c}{ Variable } & Time Period & Correlation Coefficient \\
\hline Ivittuut DJFM temperature & $1895-1966$ & $0.70^{\mathrm{b}}$ \\
Nuuk DJFM temperature & $1895-1966$ & $0.74^{\mathrm{b}}$ \\
Tasiilaq DJFM temperature $^{\text {Southern Gr. DJFM temperature }}{ }^{\mathrm{a}}$ & $1895-1966$ & $0.53^{\mathrm{b}}$ \\
NAO-J index DJFM & $1895-1966$ & $0.75^{\mathrm{b}}$ \\
NAO-L index DJFM & $1824-1970$ & $-0.51^{\mathrm{b}}$ \\
\hline \multicolumn{2}{c}{${ }^{\mathrm{a}}$ Mean temperature at Ivittuut, Nuuk and Tasiilaq. } & $-0.45^{\mathrm{b}}$ \\
${ }^{\mathrm{b}}$ Correlations significant at the $99.99 \%$ level. &
\end{tabular}




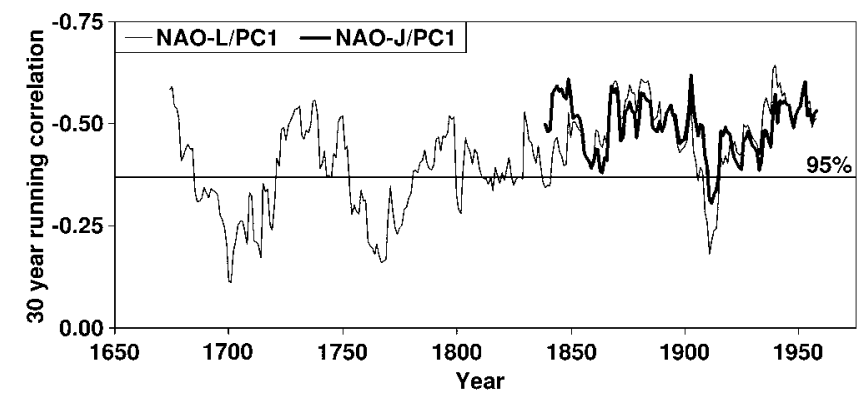

Figure 3. Running 30 year Pearson correlations between the ice core PC1 time series and December to March means of the NAO-L and NAO-J indices. Correlations numerically larger than 0.36 are significant at the $95 \%$ level.

[24] Linear regressions of North Atlantic region CRU data against the ice core based Greenland winter temperature reconstruction (the $\mathrm{PC} 1$ time series) are shown. The produced spatial response patterns of surface pressure and temperature resemble the known winter season NAO patterns.

[25] Correlations between the PC1 time series and the NAO-J index are highly significant for the 1824-1970 period and significant for almost all 30-year sub-periods. Performance of the PC1 time series with regard to the NAO$\mathrm{L}$ reconstructed index is slightly poorer. It is therefore not possible to determine whether the non-significant correlations between the PC1 time series and the NAO-L index in the early and late 18 th century is caused by changes in the NAO teleconnections affecting Greenland (and thereby the PC1) or Europe (the NAO-L). In spite of the 18th century disagreements between the PC1 time series and the NAO-L index, they are however highly significantly correlated for the full period 1659-1970.

[26] The recent multiproxy reconstruction of the NAO made by Cook et al. [2002] used a 90\% significant correlation between a given proxy and a NAO-index (similar to the NAO-J) as an initial screening criterion for proxy records. The PC1 time series as well as each of the 7 ice core winter season $\delta^{18} O$ time series are all correlated to the NAO-J at the 95\% level or better for the period 1824-1970. This combined with the good resemblance of NAO surface pressure and temperature patterns by the $\mathrm{PC} 1$ time series and the long time frame spanned by ice core data, makes the use of Greenland ice core winter season $\delta^{18} O$ data in future multiproxy NAO reconstructions very recommendable.

[27] Acknowledgments. KKA thanks the Carlsberg foundation for financial support. David Fisher and an anonymous reviewer are thanked for their helpful comments and suggestions.

\section{References}

Appenzeller, C., et al., The North Atlantic Oscillation and its imprint on precipitation and ice accumulation in Greenland, Geophys. Res. Lett., 25, 1939-1942, 1998a.
Appenzeller, C., T. F. Stocker, and M. Anklin, North Atlantic Oscillation dynamics recorded in Greenland ice cores, Science, 282, 446-449, 1998 b.

Barlow, L. K., et al., The North Atlantic Oscillation signature in deuterium and deuterium excess signals in the Greenland Ice Sheet Project 2 ice core, 1840-1970, Geophys. Res. Lett., 20, 2901-2904, 1993.

Barlow, L. K., et al., Aspects of climate variability in the North Atlantic Sector: Discussion and relation to the Greenland Ice Sheet Project 2 high resolution isotopic signal, J. Geophys. Res., C12, 26,333-26,344, 1997. Cook, E. R., R. D. D’Arrigo, and M. E. Mann, A Well-Verified, Multiproxy Reconstruction of the Winter North Atlantic Oscillation Index since A.D. 1400, J. Climate, 15, 1754-1764, 2002.

Dansgaard, W., Stable isotopes in precipitation, Tellus, 16/4, 436-468, 1964.

Fisher, D. A., High-resolution multiproxy climatic records from ice cores, tree-rings, corals and documentary sources using eigenvector techniques and maps: assessment of recovered signal and errors, The Holocene, 12, 401-419, 2002

Fisher, D. A., et al., Inter-comparison of Ice Core $\delta^{18} O$ and Precipitation Records from Sites in Canada and Greenland over the last 3500 years and over the last few Centuries in detail using EOF Techniques, NATO ASI Series, Vol. 141, 297-328, 1996.

Frich, P., et al., North Atlantic Climatological Dataset (NACD Version 1) Final Report, Scientific Report 96-1 from the Danish Meteorological Institute, 1996.

Glueck, M. F., and C. W. Stockton, Reconstruction of the North Atlantic Oscillation, 1429-1983, Int. J. Climatol., 21, 1453-1465, 2001.

Hammer, C. U., et al., Dating of Greenland ice cores by flow models, isotopes, volcanic debris, and continental dust, J. Glaciol., 20, 3-26, 1978.

Johnsen, S. J., W. Dansgaard, and J. W. C. White, The origin of Arctic precipitation under present and glacial conditions, Tellus, 41B, 452-468, 1989.

Johnsen, S. J., et al., Irregular glacial interstadials recorded in a new Greenland ice core, Nature, 359, 311-313, 1992.

Johnsen, S. J., et al., Stable Isotope Records from Greenland Deep Ice Cores: The Climate Signal and the Role of Diffusion, NATO ASI Series, Vol. 156, 89-107, 1999.

Jones, P. D., The early twentieth century Arctic High - fact or fiction?, Clim. Dyn., 1, 63-75, 1987.

Jones, P. D., T. Jonsson, and D. Wheeler, Extension to the North Atlantic Oscillation using early instrumental pressure observations from Gibraltar and south-west Iceland, Int. J. Climatol., 17, 1433-1450, 1997.

Jones, P. D., et al., Surface air temperature and its changes over the past 150 years, Rev. Geophys., 37, 173-199, 1999.

Luterbacher, J., et al., Reconstruction of Monthly NAO and EU Indices back to AD 1675, Geophys. Res. Lett., 26, 2745-2748, 1999.

Luterbacher, J., et al., Extending North Atlantic Oscillation reconstructions back to 1500, Atmos. Sci. Lett., 2, 114-124, 2002.

Osborn, T. J., et al., Evaluation of the North Atlantic Circulation as simulated by a coupled climate model, Clim. Dyn., 15, 685-702, 1999.

Peterson, T., and R. S. Vose, An overview of the Global Historical Climatology Network temperature database, Bull. Amer. Meteorol. Soc., 78, 2837-2849, 1997.

Rogers, J. C., J. F. Bolzan, and V. A. Pohjola, Atmospheric circulation variability associated with shallow-core seasonal isotopic extremes near Summit, Greenland, J. Geophys. Res., D10, 11,205-11,219, 1998.

Schmutz, C., et al., Can we trust proxy-based NAO index reconstructions?, Geophys. Res. Lett., 8, 1135-1138, 2000.

Steffensen, J. P., Microparticles in snow from the South Greenland ice sheet, Tellus, 37B, 286-295, 1985.

White, J. W. C., et al., The climate signal in the stable isotopes of snow from Summit, Greenland: Results of comparisons with modern climate observations, J. Geophys. Res., 102, 26,425-26,439, 1997.

B. M. Vinther, S. J. Johnsen, K. K. Andersen, H. B. Clausen, and A. W. Hansen, Niels Bohr Institute for Astronomy, Physics and Geophysics, Juliane Maries Vej 30, DK-2100 Copenhagen Oe., Denmark. (bo@gfy.ku. $\mathrm{dk})$ 